\title{
Moving beyond the age-depth model paradigm in deep-sea palaeoclimate archives: dual radiocarbon and stable isotope analysis on single foraminifera
}

\author{
Bryan C. Lougheed ${ }^{1,2, *}$, Brett Metcalfe ${ }^{2,3, *}$, Ulysses S. Ninnemann ${ }^{4}$, and Lukas Wacker ${ }^{5}$ \\ ${ }^{1}$ Department of Earth Sciences, Uppsala University, Villavägen 16, 75236 Uppsala, Sweden \\ ${ }^{2}$ Laboratoire des Sciences du Climat et de l'Environnement, LSCE/IPSL, CEA-CNRS-UVSQ, \\ Université Paris-Saclay, 91190 Gif-sur-Yvette, France \\ ${ }^{3}$ Department of Earth Sciences, Faculty of Sciences, Vrije Universiteit Amsterdam, De Boelelaan 1085, \\ 1081HV Amsterdam, the Netherlands \\ ${ }^{4}$ Department of Earth Science, University of Bergen, Allégaten 41, 5007 Bergen, Norway \\ ${ }^{5}$ Laboratory for Ion Beam Physics, ETH Zürich, Otto-Stern-Weg 5, 8093 Zürich, Switzerland \\ ${ }^{*}$ These authors contributed equally to this work.
}

Correspondence: Bryan C. Lougheed (bryan.lougheed@lsce.ipsl.fr)

Received: 25 September 2017 - Discussion started: 29 September 2017

Revised: 26 February 2018 - Accepted: 3 April 2018 - Published: 20 April 2018

\begin{abstract}
Late-glacial palaeoclimate reconstructions from deep-sea sediment archives provide valuable insight into past rapid changes in ocean chemistry. Unfortunately, only a small proportion of the ocean floor with sufficiently high sediment accumulation rate (SAR) is suitable for such reconstructions using the long-standing age-depth model approach. We employ ultra-small radiocarbon $\left({ }^{14} \mathrm{C}\right)$ dating on single microscopic foraminifera to demonstrate that the long-standing age-depth model method conceals large age uncertainties caused by post-depositional sediment mixing, meaning that existing studies may underestimate total geochronological error. We find that the age-depth distribution of our ${ }^{14} \mathrm{C}$-dated single foraminifera is in good agreement with existing bioturbation models only after one takes the possibility of Zoophycos burrowing into account. To overcome the problems associated with the age-depth paradigm, we use the first ever dual ${ }^{14} \mathrm{C}$ and stable isotope $\left(\delta^{18} \mathrm{O}\right.$ and $\left.\delta^{13} \mathrm{C}\right)$ analysis on single microscopic foraminifera to produce a palaeoclimate time series independent of the age-depth paradigm. This new state of the art essentially decouples single foraminifera from the age-depth paradigm to provide multiple floating, temporal snapshots of ocean chemistry, thus allowing for the successful extraction of temporally accurate palaeoclimate data from low-SAR deep-sea archives. This new method
\end{abstract}

can address large geographical gaps in late-glacial benthic palaeoceanographic reconstructions by opening up vast areas of previously disregarded, low-SAR deep-sea archives to research, which will lead to an improved understanding of the global interaction between oceans and climate.

\section{Introduction}

The past seven decades in palaeoceanography research have produced a wealth of valuable palaeoclimate data from the calcareous, foraminiferal ooze contained in deep-sea sediment archives, greatly improving our understanding of past ocean chemistry and palaeoclimate (Bond et al., 1993; Emiliani, 1955; Epstein et al., 1951; Shackleton, 1967; Urey, 1947). The long-standing geochronological method that has been applied to these sediment archives since the inception of palaeoceanography as a field of study, the age-depth model method, relies on the geological law of superposition. This law states that sediment age increases progressively with sediment core depth. The age-depth model method, as applied to deep-sea sediment cores, involves first slicing sediment cores into discrete core depth intervals of $1 \mathrm{~cm}$ thickness or greater. Sufficient numbers of suitable foraminifera tests are subsequently picked from 
select intervals and analysed using mass spectrometry, whereby ages are inferred by orbital tuning of $\delta^{18} \mathrm{O}$ values (Martinson et al., 1987; Pisias et al., 1984) and/or ${ }^{14} \mathrm{C}$ dating. Finally, statistical methods (e.g. Blaauw and Christen, 2011; Bronk Ramsey, 2008) are used to interpolate ages for all discrete depth intervals of the sediment core.

Post-depositional sediment mixing (PDSM) of deepsea archives (due to, e.g., bioturbation) can cause the relationship between sediment core age and sediment core depth to become more complex, thereby limiting the precise application of the law of superposition. This complexity can be hidden from researchers who use the age-depth model method because successful stable isotope ratio mass spectrometry (IRMS) or ${ }^{14} \mathrm{C}$ accelerator mass spectrometry (AMS) analysis has traditionally required the analysis of multi-specimen samples containing tens (Metcalfe et al., 2015; Waelbroeck et al., 2005) and hundreds (Hughen et al., 2006) of foraminifera tests, respectively. IRMS and AMS analyses only report a mean sample value and a machine measurement error, meaning that no information is provided about the true heterogeneity of the sample, which is chiefly a function of sediment accumulation rate (SAR) and PDSM. As such, the true age uncertainty within a sediment core can remain hidden from the researcher. Furthermore, AMS analysis reports a sample's mean ${ }^{14} \mathrm{C}$ activity, which is not the same as a sample's mean ${ }^{14} \mathrm{C}$ age, which creates further complications for highly heterogeneous samples (as alluded to by reviewer Ascough, 2017).

Considering the aforementioned complications associated with the age-depth model method, high-resolution sampling of core depth does not necessarily translate into highresolution sampling of time. Researchers are aware that the concealment of intra-sample age heterogeneity can pose problems for the age-depth model method (Bard, 2001; Keigwin and Gagnon, 2015; Löwemark and Grootes, 2004; Löwemark and Werner, 2001; Pisias, 1983; Ruddiman and Glover, 1972), which can potentially lead to incorrect interpretations of temporal climate offsets as well as apparent ${ }^{14} \mathrm{C}$ age offsets between different species and/or sizes of foraminifera that are, in fact, an artefact of PDSM (Berger, 1977; Löwemark et al., 2008; Löwemark and Grootes, 2004; Peng and Broecker, 1984). With these problems in mind, researchers seeking to reconstruct rapid (i.e. submillennial and centennial) climate processes have generally concentrated on sediment archives with a SAR greater than $10 \mathrm{~cm} \mathrm{ka}^{-1}$ (Hodell et al., 2015; Shackleton et al., 2000; Vautravers and Shackleton, 2006), with the assumption that a high SAR minimises the effects of PDSM upon age-depth models. However, the inability to directly quantify intrasample age heterogeneity means that this assumption has yet to be rigorously tested. Furthermore, the vast majority of the ocean floor exhibits a SAR of less than $10 \mathrm{~cm} \mathrm{ka}^{-1}$ (Fig. 1), meaning that many potentially useful study sites above the calcite compensation depth are essentially rendered unusable by the long-standing age-depth approach. Concentrating only on the select parts of the ocean floor with a high SAR introduces a geographical bias into our understanding of global ocean processes.

In this study, we utilise the latest developments in ultrasmall $\left(<100 \mu \mathrm{g} \mathrm{CaCO}_{3}\right)$ sample ${ }^{14} \mathrm{C}$ dating (Synal et al., 2007; Wacker et al., 2013a, b, c) to reduce sample size to a single benthic foraminifer specimen (Cibicidoides wuellerstorfi), thereby allowing us to directly quantify intrasample age heterogeneity and analyse PDSM in the case of the low-SAR $\left(\sim 1-2 \mathrm{~cm} \mathrm{ka}^{-1}\right)$ sediment core T86-10P from the Azores region of the North Atlantic (Fig. 1). We discuss the consequences of our results for existing studies and provide suggestions for adding realistic geochronological errors to existing deep-sea palaeoclimate records that have applied the long-standing age-depth model method involving multi-specimen samples. Furthermore, we analyse both ${ }^{14} \mathrm{C}$ and stable isotopes on select single-foraminifer specimens of sufficient mass, demonstrating the feasibility to construct palaeoclimate time series that are completely independent of the age-depth paradigm and its associated problems.

\section{Method}

\subsection{Sediment core selection and subsampling}

Sediment core T86-10P (Fig. 1) was retrieved from the North Atlantic $\left(37^{\circ} 8.13^{\prime} \mathrm{N}, 29^{\circ} 59.15^{\prime} \mathrm{W} ; 2610 \mathrm{~m}\right.$ b.s.l.) by the vessel R/V Tyro as part of the APNAP-I project. We chose core T86-10P for this study because preliminary oxygen isotope measurements on planktonic foraminifera indicated a poor multi-specimen glacial-interglacial $\delta^{18} \mathrm{O}$ stratigraphy, typical of a low-SAR sediment core (Metcalfe, 2013). Also, the nearby presence of a very high SAR record at a similar water depth (Repschläger et al., 2015) provides an ideal local "reference" stratigraphy for direct comparison. In other words, core T86-10P is an ideal sediment core with which to test the ability of dual ${ }^{14} \mathrm{C}$ and stable isotope analysis on single foraminifera to successfully extract temporally accurate palaeoclimate data from a very low-SAR archive.

A total of 185 single-specimen benthic foraminifera tests (Cibicidoides wuellerstorfi, the same species used in Repschläger et al., 2015) ranging between 25 and $500 \mu \mathrm{g}$ in mass were retrieved from the wet-sieved and deionised water-washed $>250 \mu \mathrm{m}$ fraction of $1 \mathrm{~cm}$ slices of the sediment core. Overall, 47 discrete $1 \mathrm{~cm}$ intervals were picked for foraminifera, with an average of 3.9 specimens per discrete interval being picked (min. 1 specimen, max. 10 specimens). Care was taken to pick whole tests that exhibited neither physical damage nor visible dissolution. Of these 185 tests, 100 were measured for stable isotopes only $\left(\delta^{18} \mathrm{O}\right.$ and $\left.\delta^{13} \mathrm{C}\right)$ and 49 were measured for ${ }^{14} \mathrm{C}$ only, while 36 tests were successfully analysed for both ${ }^{14} \mathrm{C}$ and stable isotopes. These 36 tests were cut using a scalpel to remove chamber(s) following established methods (e.g. 


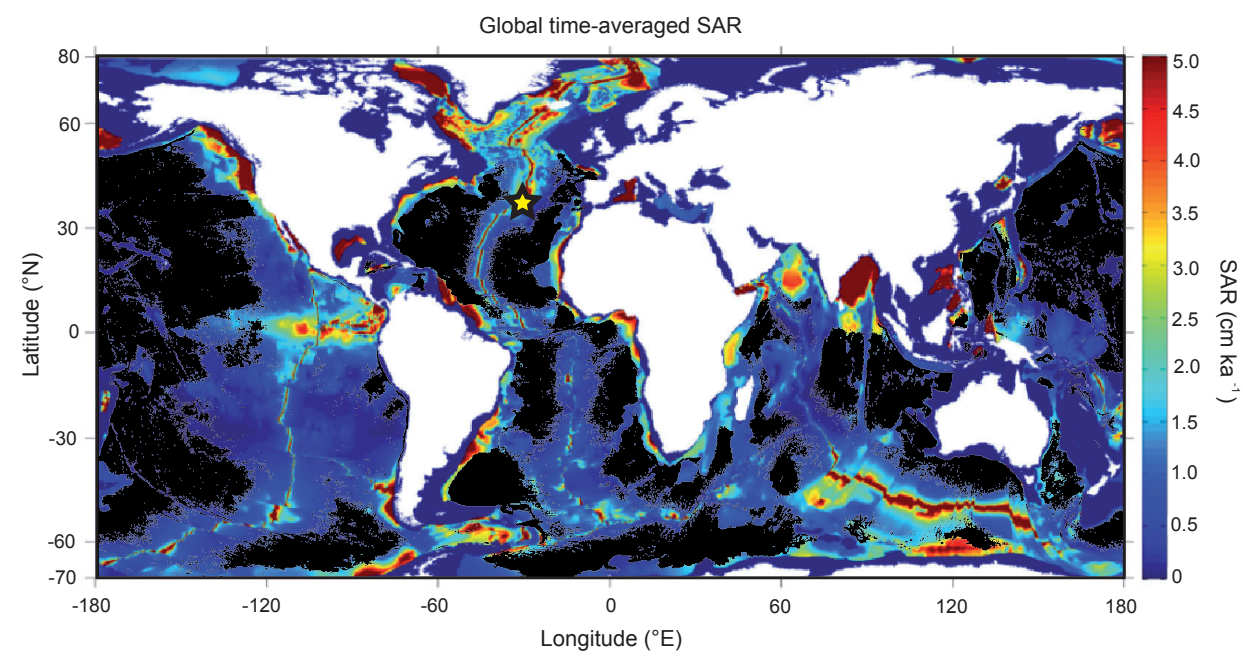

Figure 1. Map of time-averaged deep-sea sediment accumulation rates (SARs) adapted from Olson et al. (2016). Note that continental margins are not included in the SAR estimate. Superimposed on this map in black is an approximate indication of seafloor areas under the calcite compensation depth, estimated using a global water depth of $4500 \mathrm{~m}$ derived from global bathymetry (General Bathymetric Chart of the Oceans, 2015). The location of core T86-10P $\left(37^{\circ} 8.13^{\prime} \mathrm{N}, 29^{\circ} 59.15^{\prime} \mathrm{W} ; 2610 \mathrm{~m}\right.$ b.s.l. $)$ is indicated by a yellow star.

Shuxi and Shackleton, 1990; Spero and Lea, 1993; Takagi et al., 2015, 2016) according to an approximate $80 / 20$ ratio, with the larger fraction being reserved for ${ }^{14} \mathrm{C}$ AMS analysis and the smaller fraction being reserved for stable isotope IRMS analysis. Future work may instead use a more efficient splitting method based on gaseous splitting of acidified single foraminifera. All data are available in spreadsheet format in Table S1 in the Supplement.

\section{$2.2{ }^{14} \mathrm{C}$ analysis}

AMS analysis was carried out at the Laboratory for Ion Beam Physics at ETH Zürich using a permanent magnetequipped Mini Carbon Dating System (MICADAS) AMS (Synal et al., 2007) with a helium stripping system, coupled to an Ionplus carbonate handling system (Wacker et al., 2013a). This MICADAS configuration allows for direct ${ }^{14} \mathrm{C}$ measurement, using a gas ion source (Wacker et al., 2013b), of gaseous $\mathrm{CO}_{2}$ liberated from $\mathrm{CaCO}_{3}$ samples by acidification with phosphoric acid - i.e. no graphitisation step is necessary. The exclusion of the graphitisation step allows for the required sample mass to be reduced down to $100 \mu \mathrm{g}$ of $\mathrm{CaCO}_{3}(12 \mu \mathrm{g} \mathrm{C})$ and less (Lougheed et al., 2012; Wacker et al., 2013c), enabling sample size to be reduced to one specimen in the case of a suitable foraminifera species and specimen. In the time since the aforementioned small sample mass studies, both measurement sensitivity and stability have been further improved on the latest MICADAS model thanks to the addition of a helium stripping system and permanent magnets. In our study, procedural singlespecimen foraminifera blank samples (assumed Eemian age) from core T86-10P indicated a mean blank value of $0.0115 \mathrm{~F}^{14} \mathrm{C}(n=10)$. Procedural IAEA-C1 standard blank material of similar mass as the single-foraminifera tests yielded a mean blank value of $0.0100 \mathrm{~F}^{14} \mathrm{C}(n=10)$. No relationship was found between blank mass and blank value. Representative blanks (i.e. those not affected by flux jumps, etc.) were pooled and a specific blank correction of $0.0095 \pm 0.002 \mathrm{~F}^{14} \mathrm{C}$ was applied to most of the samples using the BATS software (Wacker et al., 2010). In the case of a small group of remaining samples, which came from a second run (those with lab code prefix ETH-74), a lower blank correction $\left(\mathrm{F}^{14} \mathrm{C}=0.0033 \pm 0.001\right)$ was applied. Reported ${ }^{14} \mathrm{C}$ ages (Table $\mathrm{S} 1$ ) are rounded following standard conventions (Stuiver and Polach, 1977). Research is ongoing regarding the achievement of a superior blank value for such small samples, which would allow us to improve precision and further push back the age limit of single-foraminifera ${ }^{14} \mathrm{C}$ analysis. The blank values we have achieved in this study, however, are sufficient for quantifying PDSM and reconstructing deglacial processes (i.e. the past $20 \mathrm{ka}$ ) in the low-SAR core T86-10P. Our ${ }^{14} \mathrm{C}$ measurement precision is 1 order of magnitude smaller than the reconstructed PDSM, while the general geochronological uncertainties associated with ${ }^{14} \mathrm{C}$ age calibration of marine samples (i.e. reservoir age and calibration curve uncertainties) are generally greater than our measurement uncertainty. It could be argued that high-precision ${ }^{14} \mathrm{C}$ analysis within the marine realm is not strictly necessary. Moreover, especially when studying highly heterogeneous material, such as ocean sediment core material, sacrificing precision to reduce sample size to one specimen translates to more accurate results than when one carries out high-precision measurements on multispecimen samples. In the latter case one loses all information regarding the true age precision, i.e. the intra-sample age 
heterogeneity. We carried out experiments to investigate the possible presence of secondary carbonate phases in our samples; select single specimens $(n=5)$ of sufficient size were ${ }^{14} \mathrm{C}$ analysed for both an initial phosphoric acid leach fraction and the residual foraminifer fraction. Of these five specimens, three specimens yielded leach and residual ${ }^{14} \mathrm{C}$ ages that were not significantly different within $1 \sigma$ and a fourth specimen was not significantly different within $2 \sigma$ (the fifth specimen was not significantly different within $2.1 \sigma)$.

Benthic C. wuellerstorf ${ }^{14} \mathrm{C}$ ages were calibrated using MatCal 2.2 (Lougheed and Obrochta, 2016), employing the Marine13 (Reimer et al., 2013) ${ }^{14} \mathrm{C}$ calibration curve and an appropriate marine reservoir age $\left(\Delta R=35 \pm 290{ }^{14} \mathrm{C} \mathrm{yr}\right)$, the latter of which was calculated as follows: previous studies in this region using planktonic foraminifera have employed the standard marine calibration curve (i.e. $\Delta R=0 \pm 0$ ), but the possibility of spatiotemporally dynamic $\Delta R$ for the Azores region has been alluded to previously (Schwab et al., 2012; Waelbroeck et al., 2001). We are aware of the potential uncertainties associated with $\Delta R$, so we employ a planktonic $\Delta R$ with a large uncertainty: $0 \pm 200{ }^{14} \mathrm{C}$ yr. Seeing as we carried out our investigation upon benthic foraminifera, we must additionally take into account the possibility that benthic $\Delta R$ may be different from that of the ocean's surface mixed layer for which Marine13 was developed. Using available data from a nearby sediment core from the Azores region (MD08-3180) (Sarnthein et al., 2015), we analyse ${ }^{14} \mathrm{C}$ determinations from a late-glacial sequence of co-occurring benthic and planktonic foraminifera (Supplement S1 and Fig. S1). We find that the long-term $(7 \mathrm{ka})$ average ${ }^{14} \mathrm{C}$ age difference between the planktonic and benthic foraminifera is $35 \pm 210{ }^{14} \mathrm{Cyr}$, suggesting that there is only a small absolute difference between benthic and planktonic ${ }^{14} \mathrm{C}$ ages in this region but with considerable variation. We arrive at our final benthic $\Delta R$ by correcting our planktonic $\Delta R$ $\left(0 \pm 200{ }^{14} \mathrm{C}\right.$ yr $)$ for the benthic offset $\left(35 \pm 210{ }^{14} \mathrm{C}\right.$ yr $)$ with error propagation, resulting in a final $\Delta R$ of $35 \pm 290{ }^{14} \mathrm{C}$ yr.

\subsection{Stable isotope analysis}

IRMS analysis on the smaller foraminifera test fractions from the cut tests (as well as some whole tests) was carried out at the stable isotope laboratory of the Department of Earth Science, University of Bergen, using a Kiel IV carbonate device coupled to a Thermo MAT-253 dual inlet IRMS. The use of a dual-inlet IRMS, as opposed to a continuous-flow IRMS, leads to a reduced size difference between sample and standard gas, combined with a continuous switching between standard and sample gas, which enables a higher analytical precision for small samples. Procedural standard samples (Carrara marble powder) of representative mass indicated an external precision $(1 \sigma)$ better than $0.10 \%$ and $0.05 \%$ for $\delta^{18} \mathrm{O}$ and $\delta^{13} \mathrm{C}$, respectively. Additional whole tests were analysed using a GasBench II preparation device coupled to a continuous-flow Thermo Delta Plus mass spectrometer at the Department of Earth Sciences, Vrije Universiteit Amsterdam. For these measurements, the external precision $(1 \sigma)$ of international standards was better than $0.12 \%$ o for both $\delta^{18} \mathrm{O}$ and $\delta^{13} \mathrm{C}$ (Feldmeijer et al., 2015; Metcalfe et al., 2015). All IRMS measurements are reported in per mil (\%o) against the Vienna Pee Dee Belemnite (V-PDB) scale.

\section{Results and discussion}

\subsection{Age uncertainties concealed by the long-standing geochronological method}

${ }^{14} \mathrm{C}$ analysis carried out on 85 single-specimen foraminifera tests for core T86-10P (Fig. 2a, Table S1) indicate the presence of significant PDSM, with the average standard deviation for all discrete $1 \mathrm{~cm}$ core depth intervals containing three or more ${ }^{14} \mathrm{C}$ dates being $4667{ }^{14} \mathrm{C}$ yr. We show that such significant PDSM can be concealed by longstanding geochronological methods. Specifically, we imitate the age-depth model approach involving multi-specimen samples by averaging all uncalibrated single-specimen ${ }^{14} \mathrm{C}$ data from discrete depths with three or more measured single specimens into pseudo multi-specimen ${ }^{14} \mathrm{C}$ dates with an uncertainty of $60{ }^{14} \mathrm{C}$ yr (a typical AMS machine error for larger samples). We subsequently calibrate these pseudo multi-specimen dates and produce a Bayesian agedepth model for core T86-10P (Fig. 2b) using the Bacon software (Blaauw and Christen, 2011). This age model displays an apparent average SAR of $2.2 \pm 0.9 \mathrm{~cm} \mathrm{ka}^{-1}$, with higher apparent SAR in the uppermost $10 \mathrm{~cm}$ of the core than the lower parts of the core, which is consistent with typically observed sediment mixed-layer depths (e.g. Trauth et al., 1997). Considering the large intra-sample heterogeneity present in core T86-10P, our pseudo multi-specimen Bayesian age-depth model exhibits unrealistically well-constrained confidence intervals, thus concealing the true age-depth variation present within core T86-10P. Additionally, the Bayesian age-depth modelling routine excludes a number of pseudo multi-specimen dates as outliers. We propose that downcore multi-specimen ${ }^{14} \mathrm{C}$ dates in non-sequential temporal order may serve as useful indicators for the presence of significant PDSM throughout an entire sediment sequence, rather than being regarded as outliers related to isolated events, as is often done in the literature.

While core T86-10P may not be representative of all sediment cores, the fact that very large intra-sample age heterogeneity can be concealed by long-standing geochronological methods has significant implications for existing studies relying on the age-depth model method. We note that our pseudo multi-specimen ${ }^{14} \mathrm{C}$ dates were assembled using data from an average of four foraminifera tests each. Typically, multi-specimen samples containing many tens to hundreds of foraminifera tests are used for 



Figure 2. Results of single-foraminifera $C$. wuellerstorfi ${ }^{14} \mathrm{C}$ dating in core T86-10P. (a) ${ }^{14} \mathrm{C}$ determinations (uncalibrated) on single $C$. wuellerstorfi foraminifera from core T86-10P, with $1 \sigma$ measurement uncertainty shown. (b) A demonstration of the concealment of large intra-sample heterogeneity by the long-standing geochronological method. Calibrated single-specimen benthic foraminifera ${ }^{14} \mathrm{C}$ ages $($ light blue probability density functions (PDFs); see "Method" section for ${ }^{14} \mathrm{C}$ calibration process) for all discrete $1 \mathrm{~cm}$ core depths with three or more subsampled foraminifera. To demonstrate the potential concealment of PDSM by long-standing geochronological methods involving dating of multi-specimen foraminifera samples, we also show the $95 \%$ confidence interval (light grey) of a Bacon (Blaauw and Christen, 2011) age-depth model created using calibrated pseudo multi-specimen foraminifera ${ }^{14} \mathrm{C}$ ages (black PDFs - see Sect. 3.1 ).

${ }^{14} \mathrm{C}$ dating. Were such large sample sizes to be applied to $\mathrm{T} 86-10 \mathrm{P}$, it is possible that no age-depth outliers would be produced and that all information about intrasample heterogeneity would be lost, thus concealing the full temporal uncertainty from the researcher. Such an affect was seen in one of the earliest studies using ultrasmall ${ }^{14} \mathrm{C}$ dating of foraminifera samples (Lougheed et al., 2012), whereby downcore age-depth reversals were found for a sequence of multi-specimen samples with $<500 \mu \mathrm{g}$ mass, whereas a sequence of multi-specimen samples with a greater mass did not exhibit such a behaviour. We carried out simulations to investigate the influence of ${ }^{14} \mathrm{C}$ sample size upon the concealment of age-depth outliers by using multiple simulated synthetic sediment core scenarios whereby exaggerated single-foraminifera PDSM is generated using Gaussian noise (Supplement S2 and Fig. S2). These preliminary simulations suggest that when sample size is 5 to 10 specimens or more, no age-depth outliers are present in a simulated sediment core with intense PDSM.

\subsection{Core T86-10P in the context of existing bioturbation understanding}

Seeing as it has not been previously possible to ${ }^{14} \mathrm{C}$ date single foraminifera, past research of PDSM has focussed on quantifying bioturbation processes by constructing theo- retical models. One of the earliest models for bioturbation in deep-sea sediment cores by Berger and Heath (1968) assumes that the uppermost layer of the sediment core is uniformly mixed to a certain mixed-layer depth (typically $10 \mathrm{~cm}$ ) throughout the sedimentation history of the core. This general model of bioturbation has formed the basis for subsequent modelling investigations into vertical PDSM of sediment particles of different age (e.g. Berger and Johnson, 1978; Berger and Killingley, 1982; Guinasso and Schink, 1975; Peng et al., 1979). A general feature of these traditional bioturbation models is that the continuous application of a uniformly mixed upper layer of sediment throughout the entire sedimentation history of a given sediment archive will result in an exponential probability density function (PDF) for age at any given core depth. Such an exponential PDF will exhibit a maximum probability for younger ages, with a long tail towards older ages.

To determine if the single-foraminifera ${ }^{14} \mathrm{C}$ data we retrieved from core T86-10P can be approximated using the aforementioned bioturbation models, we have carried out a single-foraminifera sedimentation simulation using a uniform mixed-layer depth of $10 \mathrm{~cm}$ and constant SAR of $1.4 \mathrm{~cm} \mathrm{ka}^{-1}$. The SAR applied is on the low end of the SAR estimated by the Bacon age-depth model $\left(2.2 \pm 0.9 \mathrm{~cm} \mathrm{ka}^{-1}\right)$ because we considered that much of the Bacon age model also includes the interval of the sediment core within 

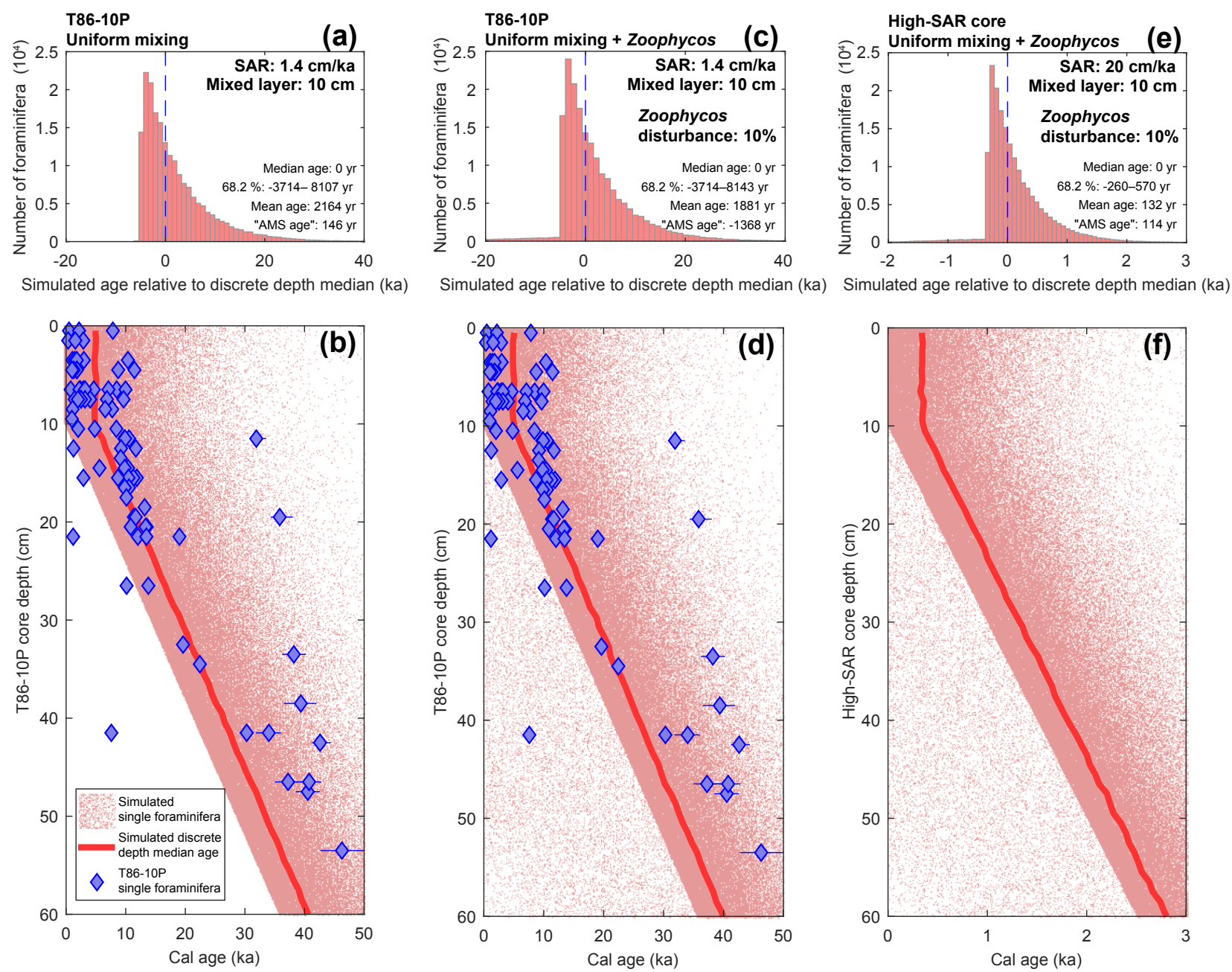

Figure 3. In order to investigate the age distribution for discrete depths of a sediment core, we carried out simulations of multiple singleforaminifera sedimentation scenarios. Each of the simulations assumes a constant SAR, with foraminifera of the same size and species. Each scenario begins at $150 \mathrm{~cm}$ core depth and continues in $0.1 \mathrm{~cm}$ intervals to $0 \mathrm{~cm}$ depth. At each $0.1 \mathrm{~cm}$ interval, 400 new synthetic foraminifera are created and assigned an age according to the SAR. At every $0.1 \mathrm{~cm}$ interval, the uppermost $10 \mathrm{~cm}$ (the assumed mixed-layer depth) of synthetic sediment core is uniformly mixed using random noise. While the simulations start at $150 \mathrm{~cm}$, we only show data to $60 \mathrm{~cm}$ depth, in order to rule out any artefacts due to simulation spin-up. (a, b) Single-foraminifera simulation using an assigned SAR of $1.4 \mathrm{~cm} \mathrm{ka}^{-1}$ and mixed-layer depth of $10 \mathrm{~cm}$. The scatter plot in (b) shows all simulated single foraminifera, along with the simulated discrete depth (1 cm depth slice) median age. Superimposed are the calibrated ages of the actual single foraminifera that we analysed in T86-10P. The histogram in (a) represents the age value of all simulated single foraminifera between 0 and $50 \mathrm{~cm}$ relative to their associated discrete $1 \mathrm{~cm}$ depth interval median age. The $68.2 \%$ percentile range, mean, median and AMS age are calculated for the histogram. AMS age is calculated by converting every single-foraminifera age value to $\mathrm{F}^{14} \mathrm{C}$, from which a mean $\mathrm{F}^{14} \mathrm{C}$ value is calculated and subsequently converted back to ${ }^{14} \mathrm{C}$ yr. For these first-order AMS age estimations, we assume that ${ }^{14} \mathrm{C}$ years are equal to calendar years (i.e. constant past $\Delta^{14} \mathrm{C}$ ). (c, d) As for (a, b) (SAR $1.4 \mathrm{~cm} \mathrm{ka}^{-1}$ and mixed-layer depth of $\left.10 \%\right)$ but with added simulation of Zoophycos burrows. Zoophycos is added post-simulation by taking $10 \%$ of all foraminifera from all depths and increasing their depth value with a random value between 0 and $50 \mathrm{~cm}$. (e, f) High-SAR single-foraminifera sedimentation simulation $\left(20 \mathrm{~cm} \mathrm{ka}^{-1}\right.$ and $10 \mathrm{~cm}$ mixed-layer depth) with Zoophycos added in the same manner as for $(\mathbf{c}, \mathbf{d})$.

the active mixed-layer depth. We consider, therefore, that $1.4 \mathrm{~cm} \mathrm{ka}^{-1}$ represents a good estimation the core SAR outside the mixed-layer depth (i.e. the SAR corresponding to the historical layers). Our simulation is carried out in sedimentation intervals of $0.1 \mathrm{~cm}$, with 400 new foraminifera being added per interval and assigned an age according to the SAR. At each sedimentation interval, the upper $10 \mathrm{~cm}$ of the sediment is uniformly mixed using random noise. The results of the simulation are presented in Fig. $3 a$ and b, and superimposed upon them are the calibrated ages for all single 
foraminifera that we have ${ }^{14} \mathrm{C}$ dated. The simulation would seem to suggest that the population of single foraminifera we have ${ }^{14} \mathrm{C}$ dated in our study cannot be approximated using a sedimentation simulation that uses only a uniformly mixedlayer depth, i.e. the method used by traditional bioturbation models. Most notably, the simulation cannot explain the downward movement of young foraminifera to great depth in T86-10P, as in the case of the specimen at $41-42 \mathrm{~cm}$ depth $(7.9 \mathrm{cal} \mathrm{ka})$ or the one at $21-22 \mathrm{~cm}$ depth $(1.2 \mathrm{cal} \mathrm{ka})$ (Fig. 3b). While we apply a constant SAR, using a dynamic SAR in our simulation would not resolve this disagreement because it would simply shift the median age towards certain ${ }^{14} \mathrm{C}$-dated single foraminifera but away from others (Fig. 3b). It is, therefore, apparent that the age-depth distribution of our single foraminifera is not fully compatible with the exponential age PDF predicted by traditional bioturbation models.

To further analyse the age-depth distribution of the ${ }^{14} \mathrm{C}$ dated single foraminifera in T86-10P, we construct an ideal superposition ranking of the single foraminifera (i.e. in the case of no PDSM) from core T86-10P by ranking them by median calibrated ${ }^{14} \mathrm{C}$ age. We can also rank the foraminifera by sediment core depth, i.e. by the $1 \mathrm{~cm}$ depth interval they were actually retrieved from. "Depth ranking" is not the same as "depth", but it nonetheless provides an interesting way to visualise the movement of single foraminifera. By comparing the age ranking and depth ranking, we can visualise the post-depositional upcore and downcore movement of the single-foraminifer tests (Fig. 4a). Analysis of the postdepositional ranking change for the foraminifera indicates that while the ranking change appears normally distributed, it just fails a statistical test for normal distribution (Fig. 4b). It would appear, therefore, that the age distribution of the single foraminifera that we have ${ }^{14} \mathrm{C}$ dated cannot be fully approximated using a normal distribution, nor by the exponential distribution suggested by traditional bioturbation models.

It may be possible that secondary bioturbation processes are contributing to the observed PDSM in T86-10P. The burrows of an unidentified organism, referred to as ichnofacies Zoophycos burrows, have been shown to penetrate much farther down into the sediment than the uniform mixed-layer depth (Löwemark and Werner, 2001; Wetzel and Werner, 1980). These burrows are often invisible to the naked eye, with $\mathrm{X}$-ray radiographs being necessary for identification. Such secondary bioturbation effects are not considered by traditional bioturbation models, a fact that researchers have previously noted (Löwemark and Grootes, 2004; Löwemark and Werner, 2001). The practical effect of Zoophycos secondary bioturbation upon a given discrete depth interval would be to introduce a population of significantly younger sediment from above (Löwemark and Schäfer, 2003), thus altering the age distribution of that discrete depth interval. The potential presence of Zoophycos may, therefore, offer an explanation for the apparent disagreement between the single-foraminifera ${ }^{14} \mathrm{C}$ age-depth relationship for core T86-10P and that predicted by our sedimentation simulation when only the traditional model of bioturbation is applied (Fig. 3b). To further investigate this possibility, we carry out a new singleforaminifera sedimentation simulation in Fig. $3 \mathrm{c}$ and d. This simulation is forced using the same SAR $\left(1.4 \mathrm{~cm} \mathrm{ka}^{-1}\right)$ and mixing layer depth $(10 \mathrm{~cm})$ parameters as the simulation previously described in Fig. 3a and b but with the addition of a post-simulation bioturbation by Zoophycos. Specifically, we take $10 \%$ of the total single-foraminifera population from the entire core and add an additional randomly selected depth of between 0 and $50 \mathrm{~cm}$ to their depth values. This process essentially serves to simulate $10 \%$ of the core sediment being bioturbated downwards by Zoophycos. The addition of the Zoophycos procedure to our simulation produces a simulated foraminifera age-depth relationship that can reconcile the presence of the young ${ }^{14} \mathrm{C}$-dated foraminifera that we find at depth in core T86-10P (Fig. 3c and d).

\subsection{Consequences for existing studies using long-standing geochronological methods}

The concealment of PDSM by long-standing geochronological methods presents significant consequences for existing studies that use stratigraphic and geochronological data sourced from deep-sea sediment archives to reconstruct rapid changes in palaeoclimate. Many recent such studies (e.g. Barker et al., 2015; Caley et al., 2012; Simon et al., 2016) use tuning to the LR04 (Lisiecki and Raymo, 2005) benthic stack to produce an age-depth chronology. We have rerun our single-foraminifera sedimentation simulation using the average SAR of LR04 $\left(3.9 \mathrm{~cm} \mathrm{ka}^{-1}\right)$ and found that one could expect a relative $68.2 \%$ age range of -1330 to $2950 \mathrm{yr}$ for discrete $1 \mathrm{~cm}$ depth intervals. When tuning to LR04, one must also consider any uncertainties related to the tuning process itself, which may be on the order of multiple millennia (Blaauw, 2012; Martinson et al., 1987; Pisias et al., 1984).

For some continental margin sites, such as those on the Iberian Margin, SAR is very high $\left(20-30 \mathrm{~cm} \mathrm{ka}^{-1}\right)$, and such study sites have been used for centennial resolution age-depth climate reconstructions (i.e. \pm 50 years precision), with the assumption that a high SAR essentially minimises the effect of bioturbation upon age-depth reconstructions (Hodell et al., 2015; Shackleton et al., 2000; Vautravers and Shackleton, 2006). On the other hand, Bard (2001) suggests that such a high SAR can at best be used only for millennial resolution (i.e. not centennial). We have rerun our singleforaminifera sedimentation simulation using a high SAR $\left(20 \mathrm{~cm} \mathrm{ka}^{-1}\right)$ typical of Iberian Margin sites (Fig. 3e and f). These simulations suggest a relative $68.2 \%$ age range of -260 to $570 \mathrm{yr}$ for a discrete $1 \mathrm{~cm}$ depth interval.

Specifically in the case of ${ }^{14} \mathrm{C}$ dating of multispecimen samples, it is of great importance to consider the 

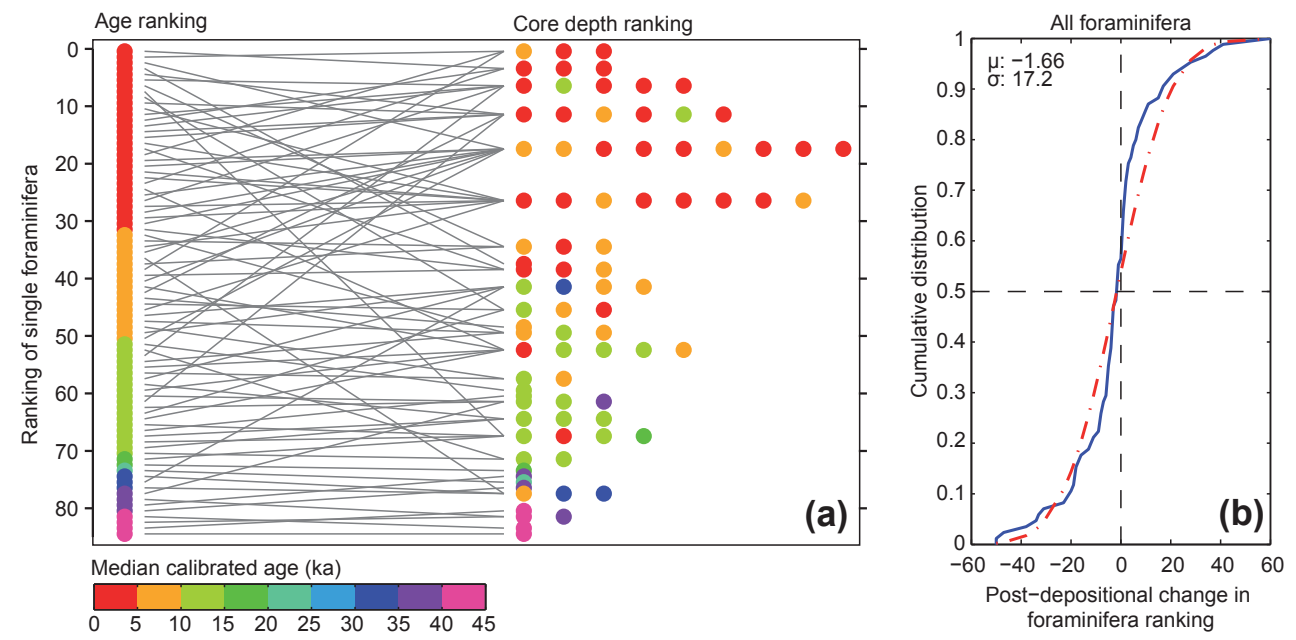

Figure 4. (a) Visualisation of PDSM in core T86-10P. Single C. wuellerstorfi benthic foraminifera (represented by coloured dots coded by median age) from core T86-10P are ranked by median calibrated age and by core depth. Single foraminifera recovered from the same core depth interval are given the same core depth ranking. Grey lines visualise the reconstructed post-depositional change in ranking. (b) Cumulative distribution plot of ranking change (as ascertained from a) for single $C$. wuellerstorfi benthic foraminifera. The blue line represents an empirical cumulative distribution of the ranking change data. The broken red line represents a fitted normal cumulative distribution function (CDF) based on the mean and standard deviation of the ranking change data. Kolmogorov-Smirnov (K-S) testing is used to test a null hypothesis of the fitted normal distribution being similar to the empirical data. Hence, a $P$ value greater than 0.05 (i.e. not less than or equal to) indicates normal distribution of the data at the $\alpha=0.05$ significance level. K-S test result: $P=0.047$; not greater than 0.05 .

heterogeneity of the age distribution of a discrete sediment interval. Radiocarbon laboratory results are based on the mean ${ }^{14} \mathrm{C}$ activity of a sample, to which laboratories apply the Libby half-life in order to report a radiocarbon age in ${ }^{14} \mathrm{C}$ years (hereafter, "AMS age"). ${ }^{14} \mathrm{C}$ is a radioactive isotope and its activity relationship with time is exponential, with the consequence that a highly heterogeneous multi-specimen sample may produce an AMS age that is significantly offset from the actual mean ${ }^{14} \mathrm{C}$ age of the sample. For all three sedimentation scenarios in Fig. 3a, c and e, we have calculated the relative mean age, median age and AMS age for discrete depth intervals in all three simulation scenarios, allowing us to demonstrate the behaviour of the potential AMS age bias caused by heterogeneous age distributions. Comparing the simulations in Fig. 3a and c, it is apparent that the addition of only a relatively small amount of younger material with an exponentially higher ${ }^{14} \mathrm{C}$ activity can serve to significantly shift the AMS age towards a much younger value. Researchers carrying out both ${ }^{14} \mathrm{C}$ AMS and stable isotope $\left(\delta^{18} \mathrm{O}\right.$ and $\left.\delta^{13} \mathrm{C}\right)$ analysis on multi-specimen samples from the same sediment core should, therefore, be aware that the AMS age is potentially skewed by an activity bias, while stable isotopes are not. It is paramount, therefore, to consider the age distributions of discrete depth intervals when carrying out palaeoclimate reconstructions. It is furthermore possible that, for a particular foraminifera species, the age distribution within discrete depths can change throughout the history of a sediment archive as a result of temporal changes in SAR, species abundance, mixed-layer depth, Zoophycos intensity, etc.

It must be stressed that core T86-10P represents a single sediment archive location and may not be wholly representative of all locations. Moreover, our study is based on the analysis of $C$. wuellerstorfi within the $>250 \mu \mathrm{m}$ fraction, whereas foraminifera in smaller fractions may be differently affected by PDSM (e.g. Wheatcroft, 1992). An exact quantification of the intra-sample age heterogeneity at other locations is essentially unknown because it can be concealed by long-standing geochronological methods. Furthermore, the intra-sample age heterogeneity for less consolidated sediment within actively bioturbated younger sediment sequences may differ from the intra-sample age heterogeneity for older, more consolidated sediment. We propose, therefore, that the ultra-small sample ${ }^{14} \mathrm{C}$ methods we outline in this study can be used, in combination with modelling techniques, to help quantify intra-sample age heterogeneity for various sediment sequences at other study locations (including those in the LR04 benthic stack), thus allowing for the application of a suitable downcore geochronological uncertainty. Such an approach will ultimately lead to a better temporal integration of deepsea sediment archives within the global palaeoclimate record. 

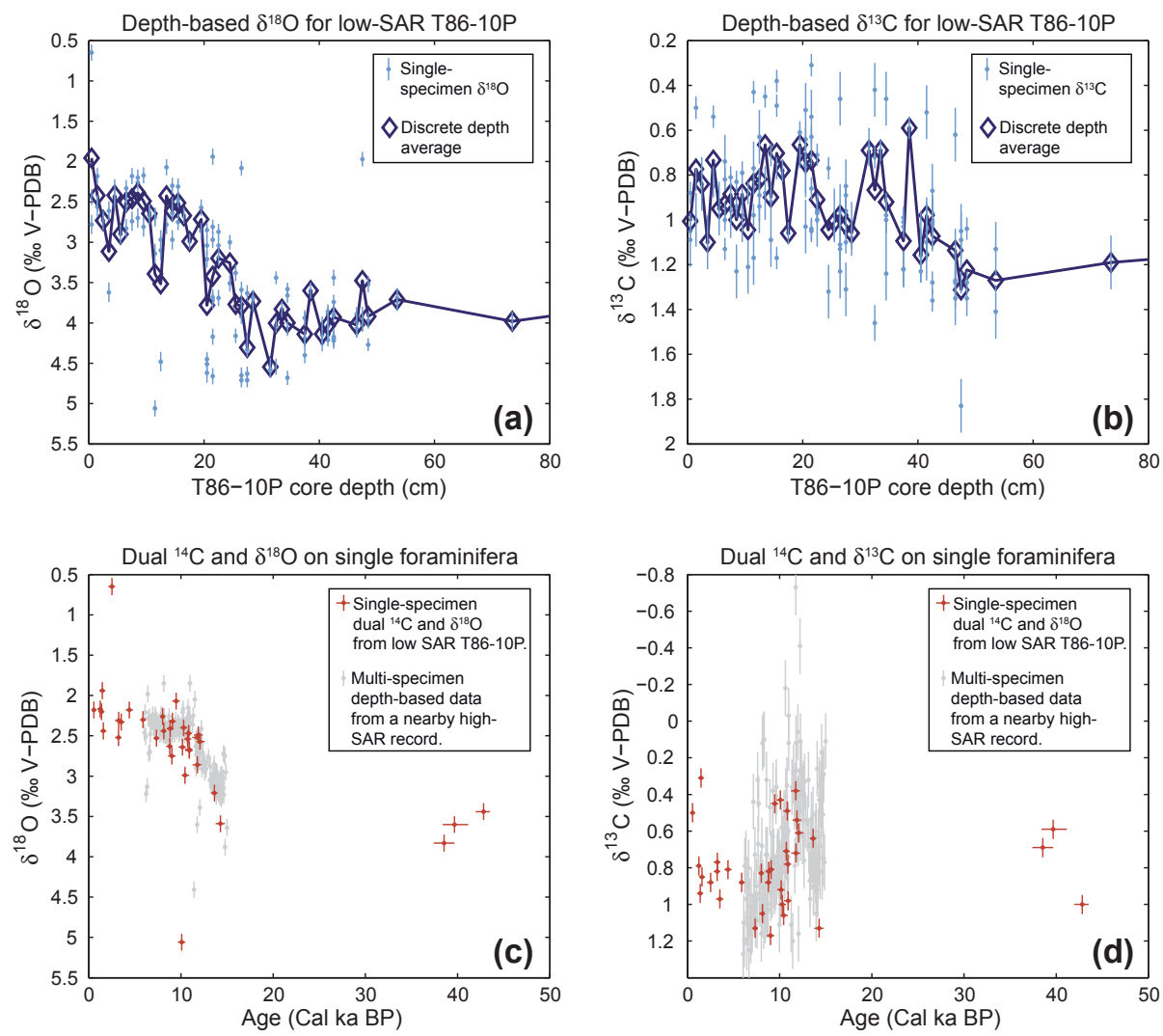

Figure 5. Demonstration of the successful use of dual ${ }^{14} \mathrm{C}$ and stable isotope analysis on single foraminifera to retrieve useful paleoclimate information from the low-SAR core T86-10P. (a) Firstly, to visualise the inability to retrieve useful glacial-interglacial paleoclimate data from the low-SAR core T86-10P using long-standing geochronological methods, we show single-specimen $C$. wuellerstorfi $\delta^{18} \mathrm{O}$ data against core depth (with $1 \sigma$ measurement error). Also shown is the average $\delta^{18} \mathrm{O}$ value of the single specimens for each discrete sediment core depth analysed (i.e. imitative of long-standing methods using multi-specimen samples). (b) Same as for (a), but with $\delta^{13} \mathrm{C}$ instead of $\delta^{18} \mathrm{O}$. (c) Successful dual ${ }^{14} \mathrm{C}$ and $\delta^{18} \mathrm{O}$ measurements on single foraminifera from core T86-10P. Vertical error bars denote $1 \sigma$ error measurement. Horizontal error bars denote the $68.27 \%$ highest posterior density (HPD) interval of the calibrated ${ }^{14} \mathrm{C}$ age (see the "Method" section for ${ }^{14} \mathrm{C}$ calibration process). Also shown are previously published multi-specimen $\delta^{18} \mathrm{O}$ data from a nearby high-SAR $\left(20 \mathrm{~cm} \mathrm{ka}^{-1}\right)$ record (Repschläger et al., 2015). Vertical error bars represent $1 \sigma$ measurement error. (d) Same as for (c), but with $\delta^{13} \mathrm{C}$ instead of $\delta^{18} \mathrm{O}$.

\subsection{Bypassing the age-depth model paradigm?}

We show that the limitations of the age-depth model paradigm essentially preclude the extraction of temporally useful deglacial benthic ventilation data from very lowSAR archives such as core T86-10P. The traditional, discrete depth average (multi-specimen) downcore stable isotope stratigraphy for core T86-10P (Fig. 5a and b) shows many spurious, large excursions in $\delta^{18} \mathrm{O}$ and $\delta^{13} \mathrm{C}$. The underlying cause for these large excursions is revealed by singlespecimen foraminifer $\delta^{18} \mathrm{O}$ and $\delta^{13} \mathrm{C}$ data (Fig. 5a and b), which show a large spread in values, an artefact of PDSM. This spread in values is significantly larger than the machine error associated with IRMS analysis (typically $0.1 \%$ ), meaning that it would be concealed by multispecimen sample IRMS analysis.

Dual measurements of both ${ }^{14} \mathrm{C}$ and stable isotopes $\left(\delta^{18} \mathrm{O}\right.$ and $\delta^{13} \mathrm{C}$ ) on the same single-specimen foraminifer in core
T86-10P can decouple an individual foraminifer from the sediment archive to provide a floating, temporal snapshot of ocean chemistry that is independent of the geological law of superposition, thereby contributing palaeoclimate information wholly independent of the age-depth paradigm. Multiple such snapshots can facilitate a time history of ocean chemistry that is completely insensitive to PDSMinduced issues involving multi-specimen samples within the age-depth paradigm, such as spurious age artefacts between foraminifera of different species, abundance changes, SAR changes, morphologies, dissolution/preservation conditions as well as particle-size-dependent mixing (Berger, 1977; Löwemark et al., 2008; Löwemark and Grootes, 2004; Peng and Broecker, 1984; Wheatcroft, 1992).

Due to the combined measurement size requirements of both AMS and IRMS, our dual ${ }^{14} \mathrm{C}$ and stable isotope measurements on single $C$. wuellerstorfi specimens were 
limited to those of sufficient mass ( $>100 \mu \mathrm{g} \mathrm{CaCO}_{3}$ ), which are generally less abundant during the coldest stadial conditions, such as the Last Glacial Maximum (LGM); a problem that also affects studies using traditional, multispecimen reconstructions (e.g. Shackleton et al., 2000). We were able to produce successful dual ${ }^{14} \mathrm{C}$ and stable isotope measurements for a sufficient number of foraminifera, revealing a $C$. wuellerstorfi benthic deglaciation signal for core T86-10P (Fig. 5c and d). This benthic deglaciation signal is in good agreement with existing $C$. wuellerstorfi data from a previous study using a nearby $(140 \mathrm{~km}$ proximity) high-SAR $\left(\sim 20 \mathrm{~cm} \mathrm{ka}^{-1}\right)$ record (Repschläger et al., 2015). Specifically, we find good temporal agreement with the absolute values for $\delta^{18} \mathrm{O}$, indicating a valid benthic deglaciation signal. We also find good temporal agreement with a sharp peak in $\delta^{13} \mathrm{C}$ values that has previously been interpreted as a local increase in Eastern North Atlantic Deep Water (ENADW) linked to the onset of the Holocene (Repschläger et al., 2015). Our results demonstrate that it is possible to use our dual ${ }^{14} \mathrm{C}$ and stable isotope method on single foraminifera to extract temporally accurate deglacial benthic palaeoceanographic data from a very low-SAR site, with success comparable to a very high-SAR site where the traditional age-depth method was used.

\section{Conclusion}

Analysis of ${ }^{14} \mathrm{C}$ on single foraminifera opens up new possibilities for quantifying the total geochronological error in existing studies due to PDSM. These errors may have been previously overlooked due to inherent limitations associated with the long-standing geochronological method based on the analysis of multi-specimen species within the agedepth paradigm. Using the methods outlined in this study it is possible to quantify the age-depth geochronological uncertainty for existing late-glacial palaeoceanographic records, as well as to consider the possibility of AMS age biases associated with very heterogeneous multispecimen samples. A full consideration of uncertainties will help to place existing palaeoceanographic records within an accurate geochronological framework. A subsequent improved evaluation of perceived regional leads and lags in palaeoceanographic processes will lead to an improved understanding of rapid climate change.

We also demonstrate that dual ${ }^{14} \mathrm{C}$ and stable isotope $\left(\delta^{18} \mathrm{O}\right.$ and $\left.\delta^{13} \mathrm{C}\right)$ measurement on single foraminifera can produce temporally accurate benthic ocean chemistry data that is independent of the age-depth paradigm. This development opens up many new avenues in late-glacial palaeoceanographic research, specifically for the vast lowSAR areas of the ocean $\left(<10 \mathrm{~cm} \mathrm{ka}^{-1}\right.$; Fig. 1$)$ that are inaccessible for research using existing methods, thus filling in large spatial gaps in the global, late-glacial climate record. The resulting improvements in spatiotemporal reconstructions of global benthic ventilation conditions of the ocean across the glacial-interglacial transition will help to better understand the interaction between the atmosphere and ocean during periods of rapid climate change.

Retrieving the entire deglacial signal from low-SAR sites using our proposed dual ${ }^{14} \mathrm{C}$ and stable isotope method may also prove to be cost effective, seeing as less elaborate sediment retrieval methods are necessary. Only the top $10-20 \mathrm{~cm}$ of the sediment archive are required and the preservation of sediment superposition is not of importance, so it may be possible to retrieve suitable sediment from the low-SAR areas of the ocean simply by using grab samples, including those already present in institutional archives. Furthermore, the method we used to ${ }^{14} \mathrm{C}$-analyse single foraminifera is efficient and cost-effective for two main reasons: (1) the elimination of the graphitisation process reduces labour and material costs; (2) the very small sample mass means that the required AMS machine analysis time is greatly reduced.

Data availability. All data generated in this study are available in spreadsheet format in Table S1 in the Supplement.

\section{The Supplement related to this article is available online at https://doi.org/10.5194/cp-14-515-2018-supplement.}

Author contributions. BCL and BM designed the study. BM picked and cut suitable foraminifera tests. $\mathrm{LW}$ and BCL carried out ${ }^{14} \mathrm{C}$ dating. BM, USN and BCL carried out stable isotope analysis. BCL analysed the data and wrote the manuscript with input from the co-authors.

Competing interests. The authors declare that they have no conflict of interest.

Acknowledgements. Measurements and Bryan C. Lougheed were funded by Swedish Research Council (Vetenskapsrådet) grant 637-2014-499 awarded to Bryan C. Lougheed. Brett Metcalfe acknowledges the Netherlands Organisation for Scientific Research (NWO) grant 822.01.0.19. Gerald M. Ganssen is thanked for providing access to core material. Claire Waelbroeck is thanked for assistance in finding planktonic-benthic ${ }^{14} \mathrm{C}$ ventilation data from the Azores region. Kevin Küssner is thanked for interesting discussions about Zoophycos. We thank the discussion contributors and designated reviewers for their valuable comments in the Climate of the Past discussions forum: Philippa Ascough, Andrew M. Dolman, Sze Ling Ho, Thomas Laepple, Julia Gottschalk and one anonymous reviewer. The town of Port Aransas, where most of this paper was written, is wished all the best in its recovery from Hurricane Harvey. 
Edited by: Alessio Rovere

Reviewed by: Philippa Ascough, Andrew Dolman, and one anonymous referee

\section{References}

Ascough, P. L.: Interactive comment on "Moving beyond the age-depth model paradigm in deep sea palaeoclimate archives: dual radiocarbon and stable isotope analysis on single foraminifera" by Bryan C. Lougheed et al., Clim. Past Discuss., https://doi.org/10.5194/cp-2017-119-RC1, 2017.

Bard, E.: Paleoceanographic implications of the difference in deep-sea sediment mixing between large and fine particles, Paleoceanography, 16, 235-239, 2001.

Barker, S., Chen, J., Gong, X., Jonkers, L., Knorr, G., and Thornalley, D.: Icebergs not the trigger for North Atlantic cold events, Nature, 520, 333-336, https://doi.org/10.1038/nature14330, 2015.

Berger, W. H.: Deep-sea carbonate and the deglaciation preservation spike in pteropods and foraminifera, Nature, 269, 301-304, 1977.

Berger, W. H. and Heath, G. R.: Vertical mixing in pelagic sediments, J. Mar. Res., 26, 134-143, 1968.

Berger, W. H. and Johnson, R. F.: On the thickness and the ${ }^{14} \mathrm{C}$ age of the mixed layer in deep-sea carbonates, Earth Planet. Sc. Lett., 41, 223-227, 1978.

Berger, W. H. and Killingley, J. S.: Box cores from the equatorial Pacific: ${ }^{14} \mathrm{C}$ sedimentation rates and benthic mixing, Mar. Geol., 45, 93-125, https://doi.org/10.1016/00253227(82)90182-7, 1982.

Blaauw, M.: Out of tune: the dangers of aligning proxy archives, Quaternary Sci. Rev., 36, 38-49, https://doi.org/10.1016/j.quascirev.2010.11.012, 2012.

Blaauw, M. and Christen, J. A.: Flexible Paleoclimate Age-Depth Models Using an Autoregressive Gamma Process, Bayesian Anal., 6, 457-474, https://doi.org/10.1214/11-BA618, 2011.

Bond, G., Broecker, W., Johnsen, S., McManus, J., Labeyrie, L., Jouzel, J. and Bonani, G.: Correlations between climate records from North Atlantic sediments and Greenland ice, Nature, 365, 143-147, 1993.

Bronk Ramsey, C.: Deposition models for chronological records, Quaternary Sci. Rev., 27, 42-60, 2008.

Caley, T., Giraudeau, J., Malaizé, B., Rossignol, L., and Pierre, C.: Agulhas leakage as a key process in the modes of Quaternary climate changes, P. Natl. Acad. Sci. USA, 109, 6835-6839, 2012.

Emiliani, C.: Pleistocene temperatures, J. Geol., 63, 538-578, 1955.

Epstein, S., Buchsbaum, R., Lowenstam, H., and Urey, H. C.: Carbonate-water isotopic temperature scale, Geol. Soc. Am. Bull., 62, 417-426, 1951.

Feldmeijer, W., Metcalfe, B., Brummer, G.-J. A., and Ganssen, G. M.: Reconstructing the depth of the permanent thermocline through the morphology and geochemistry of the deep dwelling planktonic foraminifer Globorotalia truncatulinoides, Paleoceanography, 30, 1-22, https://doi.org/10.1002/2014PA002687, 2015.

General Bathymetric Chart of the Oceans: GECBO_2014 Grid, version 20150318, available at: www.gebco.net, 2015.

Guinasso, N. L. and Schink, D. R.: Quantitative estimates of biological mixing rates in abyssal sediments, J. Geophys.
Res., 80, 3032-3043, https://doi.org/10.1029/JC080i021p03032, 1975.

Hodell, D., Lourens, L., Crowhurst, S., Konijnendijk, T., Tjallingii, R., Jiménez-Espejo, F., Skinner, L., Tzedakis, P. C., and Shackleton Site Project Members: A reference time scale for Site U1385 (Shackleton Site) on the SW Iberian Margin, Global Planet. Change, 133, 49-64, https://doi.org/10.1016/j.gloplacha.2015.07.002, 2015.

Hughen, K., Southon, J., Lehman, S., Bertrand, C., and Turnbull, J.: Marine-derived ${ }^{14} \mathrm{C}$ calibration and activity record for the past 50,000 years updated from the Cariaco Basin, Quaternary Sci. Rev., 25, 3216-3227, https://doi.org/10.1016/j.quascirev.2006.03.014, 2006.

Keigwin, L. and Gagnon, A.: Comparison of Large and Ultra-Small $\Delta^{14} \mathrm{C}$ Measurements in Core Top Benthic Foraminifera from the Okhotsk Sea, Radiocarbon, 57, 123-128, https://doi.org/10.2458/azu_rc.57.18153, 2015.

Lisiecki, L. E. and Raymo, M. E.: A Pliocene-Pleistocene stack of 57 globally distributed benthic $\delta^{18} \mathrm{O}$ records, Paleoceanography, 20, PA1003, https://doi.org/10.1029/2004PA001071, 2005.

Lougheed, B. C. and Obrochta, S. P.: MatCal: Open Source Bayesian ${ }^{14} \mathrm{C}$ Age Calibration in Matlab, J. Open Res. Softw., 4, e42, https://doi.org/10.5334/jors.130, 2016.

Lougheed, B. C., Snowball, I., Moros, M., Kabel, K., Muscheler, R., Virtasalo, J. J., and Wacker, L.: Using an independent geochronology based on palaeomagnetic secular variation (PSV) and atmospheric $\mathrm{Pb}$ deposition to date Baltic Sea sediments and infer ${ }^{14} \mathrm{C}$ reservoir age, Quaternary Sci. Rev., 42, 43-58, 2012.

Löwemark, L. and Grootes, P. M.: Large age differences between planktic foraminifers caused by abundance variations and Zoophycos bioturbation, Paleoceanography, 19, PA2001, https://doi.org/10.1029/2003PA000949, 2004.

Löwemark, L. and Schäfer, P.: Ethological implications from a detailed X-ray radiograph and ${ }^{14} \mathrm{C}$ study of the modern deep-sea Zoophycos, Palaeogeogr. Palaeocl., 192, 101-121, https://doi.org/10.1016/S0031-0182(02)00681-8, 2003.

Löwemark, L. and Werner, F.: Dating errors in high-resolution stratigraphy: a detailed X-ray radiograph and AMS- ${ }^{14} \mathrm{C}$ study of Zoophycos burrows, Mar. Geol., 177, 191-198, 2001.

Löwemark, L., Konstantinou, K. I., and Steinke, S.: Bias in foraminiferal multispecies reconstructions of paleohydrographic conditions caused by foraminiferal abundance variations and bioturbational mixing: A model approach, Mar. Geol., 256, 101106, https://doi.org/10.1016/j.margeo.2008.10.005, 2008.

Martinson, D. G., Pisias, N. G., Hays, J. D., Imbrie, J., Moore, T. C., and Shackleton, N. J.: Age dating and the orbital theory of the ice ages: development of a high-resolution 0 to 300,000-year chronostratigraphy, Quaternary Res., 27, 1-29, 1987.

Metcalfe, B.: Planktonic Foraminifera: From production to preservation of the oceanographic signal, $\mathrm{PhD}$ Thesis Vrije Univ. Amst., chap. 8, 253-274, 2013.

Metcalfe, B., Feldmeijer, W., de Vringer-Picon, M., Brummer, G.J. A., Peeters, F. J. C., and Ganssen, G. M.: Late Pleistocene glacial-interglacial shell-size-isotope variability in planktonic foraminifera as a function of local hydrography, Biogeosciences, 12, 4781-4807, https://doi.org/10.5194/bg-12-4781-2015, 2015.

Olson, P., Reynolds, E., Hinnov, L., and Goswami, A.: Variation of ocean sediment thickness with crustal age, Geochem. Geophy. 
Geosy, 17, 1349-1369, https://doi.org/10.1002/2015GC006143, 2016.

Peng, T.-H. and Broecker, W. S.: The impacts of bioturbation on the age difference between benthic and planktonic foraminifera in deep sea sediments, Nucl. Instrum. Meth. B, 5, 346-352, 1984.

Peng, T.-H., Broecker, W. S., and Berger, W. H.: Rates of benthic mixing in deep-sea sediment as determined by radioactive tracers, Quaternary Res., 11, 141-149, 1979.

Pisias, N. G.: Geologic time series from deep-sea sediments: Time scales and distortion by bioturbation, Mar. Geol., 51, 99-113, 1983.

Pisias, N. G., Martinson, D. G., Moore, T. C., Shackleton, N. J., Prell, W., Hays, J., and Boden, G.: High resolution stratigraphic correlation of benthic oxygen isotopic records spanning the last 300,000 years, Mar. Geol., 56, 119-136, 1984.

Reimer, P. J., Bard, E., Bayliss, A., Beck, J. W., Blackwell, P. G., Ramsey, C. B., Buck, C. E., Cheng, H., Edwards, R. L., Friedrich, M., Grootes, P. M., Guilderson, T. P., Haflidason, H., Hajdas, I., Hatté, C., Heaton, T. J., Hoffmann, D. L., Hogg, A. G., Hughen, K. A., Kaiser, K. F., Kromer, B., Manning, S. W., Niu, M., Reimer, R. W., Richards, D. A., Scott, E. M., Southon, J. R., Staff, R. A., Turney, C. S. M., and van der Plicht, J.: IntCal13 and Marine13 Radiocarbon Age Calibration Curves 050,000 Years cal BP, Radiocarbon, 55, 1869-1887, 2013.

Repschläger, J., Weinelt, M., Andersen, N., Garbe-Schönberg, D., and Schneider, R.: Northern source for Deglacial and Holocene deepwater composition changes in the Eastern North Atlantic Basin, Earth Planet. Sc. Lett., 425, 256-267, https://doi.org/10.1016/j.epsl.2015.05.009, 2015.

Ruddiman, W. F. and Glover, L. K.: Vertical mixing of ice-rafted volcanic ash in North Atlantic sediments, Geol. Soc. Am. Bull., 83, 2817-2836, 1972.

Sarnthein, M., Balmer, S., Grootes, P. M., and Mudelsee, M.: Planktic and Benthic ${ }^{14} \mathrm{C}$ Reservoir Ages for Three Ocean Basins, Calibrated by a Suite of ${ }^{14} \mathrm{C}$ Plateaus in the Glacial-toDeglacial Suigetsu Atmospheric ${ }^{14} \mathrm{C}$ Record, Radiocarbon, 57, 129-151, https://doi.org/10.2458/azu_rc.57.17916, 2015.

Schwab, C., Kinkel, H., Weinelt, M., and Repschläger, J.: Coccolithophore paleoproductivity and ecology response to deglacial and Holocene changes in the Azores Current System, Paleoceanography, 27, PA3210, https://doi.org/10.1029/2012PA002281, 2012.

Shackleton, N. J.: Oxygen isotope analyses and Pleistocene temperatures re-assessed, Nature, 215, 15-17, 1967.

Shackleton, N. J., Hall, M. A., and Vincent, E.: Phase relationships between millennial-scale events 64,000-24,000 years ago, Paleoceanography, 15, 565-569, 2000.

Shuxi, C. and Shackleton, N. J.: New technique for study on isotopic fractionation between sea water and foraminiferal growing processes, Chin. J. Oceanol. Limnol., 8, 299, https://doi.org/10.1007/BF02849675, 1990.

Simon, M. H., Ziegler, M., Bosmans, J., Barker, S., Reason, C. J. C., and Hall, I. R.: Eastern South African hydroclimate over the past 270,000 years, Sci. Rep., 5, 18153, https://doi.org/10.1038/srep18153, 2016.

Spero, H. J. and Lea, D. W.: Intraspecific stable isotope variability in the planktic foraminifera Globigerinoides sacculifer: Results from laboratory experiments, Mar. Micropaleontol., 22, 221234, https://doi.org/10.1016/0377-8398(93)90045-Y, 1993.
Stuiver, M. and Polach, H. A.: Discussion: Reporting of ${ }^{14} \mathrm{C}$ data, Radiocarbon, 19, 355-363, 1977.

Synal, H.-A., Stocker, M., and Suter, M.: MICADAS: A new compact radiocarbon AMS system, Nucl. Instrum. Meth. B, 259, 7-13, https://doi.org/10.1016/j.nimb.2007.01.138, 2007.

Takagi, H., Moriya, K., Ishimura, T., Suzuki, A., Kawahata, H., and Hirano, H.: Exploring photosymbiotic ecology of planktic foraminifers from chamber-by-chamber isotopic history of individual foraminifers, Paleobiology, 41, 108-121, https://doi.org/10.1017/pab.2014.7, 2015.

Takagi, H., Moriya, K., Ishimura, T., Suzuki, A., Kawahata, H., and Hirano, H.: Individual Migration Pathways of Modern Planktic Foraminifers: Chamber-by-Chamber Assessment of Stable Isotopes, Paleontol. Res., 20, 268-284, https://doi.org/10.2517/2015PR036, 2016.

Trauth, M. H., Sarnthein, M., and Arnold, M.: Bioturbational mixing depth and carbon flux at the seafloor, Paleoceanography, 12, 517-526, 1997.

Urey, H. C.: The thermodynamic properties of isotopic substances, J. Chem. Soc., 562-581, https://doi.org/10.1039/JR9470000562, 1947.

Vautravers, M. J. and Shackleton, N. J.: Centennial-scale surface hydrology off Portugal during marine isotope stage 3: Insights from planktonic foraminiferal fauna variability, Paleoceanography, 21, PA3004, https://doi.org/10.1029/2005PA001144, 2006.

Wacker, L., Christl, M., and Synal, H.-A.: Bats: A new tool for AMS data reduction, Nucl. Instrum. Meth. B, 268, 976-979, https://doi.org/10.1016/j.nimb.2009.10.078, 2010.

Wacker, L., Fülöp, R.-H., Hajdas, I., Molnár, M., and Rethemeyer, J.: A novel approach to process carbonate samples for radiocarbon measurements with helium carrier gas, Nucl. Instrum. Meth. B, 294, 214-217, https://doi.org/10.1016/j.nimb.2012.08.030, 2013 a.

Wacker, L., Fahrni, S. M., Hajdas, I., Molnar, M., Synal, H.-A., Szidat, S., and Zhang, Y. L.: A versatile gas interface for routine radiocarbon analysis with a gas ion source, Nucl. Instrum. Meth. B, 294, 315-319, https://doi.org/10.1016/j.nimb.2012.02.009, 2013 b.

Wacker, L., Lippold, J., Molnár, M., and Schulz, H.: Towards radiocarbon dating of single foraminifera with a gas ion source, Nucl. Instrum. Meth. B, 294, 307-310, https://doi.org/10.1016/j.nimb.2012.08.038, 2013c.

Waelbroeck, C., Duplessy, J.-C., Michel, E., Labeyrie, L., Paillard, D., and Duprat, J.: The timing of the last deglaciation in North Atlantic climate records, Nature, 412, 724-727, 2001.

Waelbroeck, C., Mulitza, S., Spero, H., Dokken, T., Kiefer, T., and Cortijo, E.: A global compilation of late Holocene planktonic foraminiferal $\delta^{18} \mathrm{O}$ : relationship between surface water temperature and $\delta^{18} \mathrm{O}$, Quaternary Sci. Rev., 24, 853-868, https://doi.org/10.1016/j.quascirev.2003.10.014, 2005.

Wetzel, A. and Werner, F.: Morphology and ecological significance of Zoophycos in deep-sea sediments off NW Africa, Palaeogeogr. Palaeocl., 32, 185-212, https://doi.org/10.1016/00310182(80)90040-1, 1980.

Wheatcroft, R. A.: Experimental tests for particle size-dependent bioturbation in the deep ocean, Limnol. Oceanogr., 37, 90-104, 1992. 